OPEN ACCESS

Edited by:

Cansin Sackesen,

Koç University, Turkey

Reviewed by:

Yue Zhang,

Harvard University, United States

Rosan Meyer,

Imperial College London,

United Kingdom

*Correspondence:

John O. Warner

j.o.warner@imperial.ac.uk

Specialty section:

This article was submitted to

Nutritional Immunology,

a section of the journal

Frontiers in Immunology

Received: 20 September 2020 Accepted: 04 May 2021

Published: 10 June 2021

Citation:

Zepeda-Ortega B, Goh A, Xepapadaki $P$, Sprikkelman A, Nicolaou N, Hernandez REH,

Latiff AHA, Yat MT, Diab M,

Hussaini BA, Setiabudiawan $B$, Kudla U, van Neerven RJJ, Muhardi L and Warner JO (2021) Strategies and

Future Opportunities for the

Prevention, Diagnosis, and Management of Cow Milk Allergy.

Front. Immunol. 12:608372. doi: 10.3389/fimmu.2021.608372

\section{Strategies and Future Opportunities for the Prevention, Diagnosis, and Management of Cow Milk Allergy}

\author{
Benjamin Zepeda-Ortega ${ }^{1}$, Anne Goh ${ }^{2}$, Paraskevi Xepapadaki ${ }^{3}$, Aline Sprikkelman ${ }^{4}$, \\ Nicolaos Nicolaou ${ }^{5}$, Rosa Elena Huerta Hernandez ${ }^{6}$, Amir Hamzah Abdul Latiff ${ }^{7}$, \\ Miu Ting Yat ${ }^{8}$, Mohamed Diab ${ }^{9}$, Bakr Al Hussaini ${ }^{10}$, Budi Setiabudiawan ${ }^{11,12}$, Urszula Kudla ${ }^{13}$, \\ R. J. Joost van Neerven ${ }^{13,14}$, Leilani Muhardi ${ }^{15}$ and John O. Warner ${ }^{16,17^{*}}$
}

\begin{abstract}
${ }_{1}$ Pediatric Allergist Private Practice, Angeles Lomas Hospital Huixquilucan Mexican State, Mexico City, Mexico, ${ }^{2}$ Department of Paediatrics, KKWomen's and Children's Hospital, Singapore, Singapore, ${ }^{3}$ Allergy Department, $2^{\text {nd }}$ Pediatric Clinic, National and Kapodistrian University of Athens, Athens, Greece, ${ }^{4}$ Department of Pediatric Pulmonology and Pediatric Allergology, Beatrix Children's Hospital, University Medical Center Groningen, University of Groningen, Groningen, Netherlands, ${ }^{5}$ Medical School, University of Nicosia, Nicosia, Cyprus, 6 Pediatric Allergy Clinic, Pachuca, Mexico, ${ }^{7}$ Allergy \& Immunology Center, Pantai Hospital Kuala Lumpur, Kuala Lumpur, Malaysia, ${ }^{8}$ Department of Paediatrics, Queen Elizabeth Hospital, Hong Kong, China, 9 Pediatric Department Faculty of Medicine, Children Hospital Cairo University, Cairo, Egypt, ${ }^{10}$ Department of Pediatrics, Abdul Aziz University Hospital, Jeddah, Saudi Arabia, ${ }^{11}$ Department of Child Health, Faculty of Medicine, Univesitas Padjadjaran, Bandung, Indonesia, ${ }^{12}$ Department of Pediatrics, Dr. Hasan Sadikin General Hospital, Bandung, Indonesia, ${ }^{13}$ R\&D, FrieslandCampina, Amersfoort, Netherlands, ${ }^{14}$ Wageningen University \& Research, Wageningen, Netherlands, ${ }^{15}$ Medical Affairs, Friesland Campina AMEA, Singapore, Singapore, ${ }^{16}$ Inflammation Repair and Development, National Heart and Lung Institute Imperial College, London, United Kingdom, ${ }^{17}$ Paediatrics, University of Cape Town, Cape Town, South Africa
\end{abstract}

The prevalence of food allergy has increased over the last 20-30 years, including cow milk allergy (CMA) which is one of the most common causes of infant food allergy. International allergy experts met in 2019 to discuss broad topics in allergy prevention and management of CMA including current challenges and future opportunities. The highlights of the meeting combined with recently published developments are presented here. Primary prevention of CMA should start from pre-pregnancy with a focus on a healthy lifestyle and food diversity to ensure adequate transfer of inhibitory lgG- allergen immune complexes across the placenta especially in mothers with a history of allergic diseases and planned c-section delivery. For non-breastfed infants, there is controversy about the preventive role of partially hydrolyzed formulae $(\mathrm{pHF}$ ) despite some evidence of health economic benefits among those with a family history of allergy. Clinical management of CMA consists of secondary prevention with a focus on the development of early oral tolerance. The use of extensive Hydrolysate Formulae (eHF) is the nutrition of choice for the majority of non-breastfed infants with CMA; potentially with pre-, probiotics and LCPUFA to support early oral tolerance induction. Future opportunities are, among others, pre- and probiotics supplementation for mothers and high-risk infants for the primary prevention of CMA. A controlled prospective study implementing a step-down milk formulae ladder with various degrees of hydrolysate is proposed for food challenges and early development of oral tolerance. This provides a more precise gradation of milk protein exposure than those currently recommended.

Keywords: partially hydrolysate, intermediate extensive hydrolysate, extensive hydrolysate, prevention, management, cow milk allergy, hydrolysate step-wise approach, early oral tolerance development milk ladder 


\section{INTRODUCTION}

Food allergy constitutes the second phase of increases in the prevalence of allergic diseases that have occurred over the last 60 years. Initially, asthma and allergic rhinitis increased mostly in affluent countries during the second half of the $20^{\text {th }}$ century. In some countries, the prevalence of these respiratory allergic diseases have plateaued or are falling such as in Korea, Morocco, Thailand, Australia and Brazil $(1,2)$. However, the prevalence of food allergy has increased over the last 20-30 years (3). Food allergy affects 6$8 \%$ of children worldwide and the disease burden is highest for infants and preschool-aged children (4). Cow's milk is one of the most common and early causes of infant food allergy, affecting 1.4$3.8 \%$ of young children (5-7). The Europrevall study which used rigorous ascertainment including double-blind placebo-controlled food challenge (DBPCFC) in 12,000 infants aged 24-30 months showed an overall prevalence of $0.59 \%$, ranging from $0-1.3 \%$ in different countries $(3,8)$, while similar rates have been shown in studies from Israel, Denmark and USA (9).

Cow's milk protein allergy (CMA) can be considered as an umbrella term for different diseases with distinct symptoms, pathophysiology and treatment and can be further classified as immunoglobulin E (IgE)-mediated food allergy, non-IgE mediated food allergy, or mixed IgE and non-IgE mediated food allergy (10). These immunologically mediated allergic reactions to cow milk must be distinguished from milk intolerance where a non-immune mechanism is involved, such as lactose intolerance, and from milk aversion or psychological intolerance. Food intolerance such as lactose intolerance does not involve the immune system but a deficiency of an enzyme to digest lactose. Thus, the diagnosis of milk or lactose tolerance does not involve any immune parameters, while immune-related disease involves relevant immune markers (11).

Accurate diagnosis of CMA is not easy; a detailed anamnesis and clinical history are critical to establishing the diagnosis as often, parents are not aware of various allergic manifestations (12, 13). The gastrointestinal (GI) system is most commonly affected. Some important GI symptoms include: dysphagia which presents with screaming, back-arching, gagging or choking during feeds (may be due to milk-induced eosinophilic esophagitis), vomiting, reflux, food impaction, delayed gastric emptying, abdominal pain, diarrhea, bloody stool, constipation, perianal rash, anorexia, early satiety and hematochezia, in neonates and infants (14). Moreover, discrimination of pathological from "benign" GI symptoms such as vomiting from reflux is often difficult to distinguish.

The Enquiring About Tolerance (EAT) study collected data on parental reporting of non-IgE mediated symptoms such as colic, vomiting, diarrhea and constipation. They found that infants who were encouraged to introduce cow milk and other food allergens from 4 months of age, reported significantly more non-IgE type symptoms such as eczema flares and colic, than the group which introduced allergens to complementary feeding after 6 months of exclusive breast-feeding (8.6\% compared with $3.8 \%$, respectively $(\mathrm{p}<0.001)$. This could also be due to the presence of confounding factors at such a young age (15).

Exclusively breastfed children are also at risk for CMA. While the continuation of breastfeeding with maternal elimination of cow's milk protein (CMP) was recommended (13), this has been challenged in a recent publication (16). However, exclusion depends on the child's symptom and an elimination/challenge protocol should still be done to ascertain CMA (13). For children below the age of 2 years and non-breastfed children, the main treatment in CMA remains avoidance of CMP and the use of extensively hydrolyzed formulae (eHF). The use of other alternative formulae such as soy or rice formulae needs to be considered as well, while amino acid formulae (AAF) is only recommended when the child still has symptoms of CMA on eHF or severe reactions such as anaphylactic shock $(17,18)$.

As there is a significant impact of food allergies on the quality of life of children and their families including emotional, psychological and financial burden (19-21), further study of the causes, consequences, prevention and treatment of specific food allergies such as CMA are needed.

In this paper, we report the output from a 2-day meeting with international experts in CMA from various countries in October 2019. The meeting discussed broad topics in allergy prevention and management of CMA including differences in epidemiology, cultural background, eating habits and climate change. This paper will focus on current challenges and future opportunities in CMA, its nutritional management strategies for tapering and reintroducing cow's milk proteins in the diet, and the potential for prevention which we have combined with recently published developments since the meeting. The conclusions highlight the unmet needs and consequent recommendations for future research for optimal management and prevention of CMA.

\section{THE ONTOGENY OF CMA AND THE ALLERGIC MARCH}

The immunology of a normal pregnancy involves downregulating the maternal T-helper-1 lymphocyte (Th1) response to feto-paternal antigens by upregulating T-helper-2 and regulatory T-cell cytokines. These cytokines are present in the amniotic fluid together with any antigens/allergens to which the mother has been exposed. These are swallowed by the fetus, potentially enhancing allergic sensitization through lymphoid accumulations in the small intestine. All neonates consequently have a Th-2 biased immune response which is more entrenched in an atopic maternal environment (22).

A component of balancing the response occurs in the 3rd trimester through allergen aggregated with IgG transported across the placenta which down-regulates sensitization through inhibitory IgG receptors. This being the case, high maternal intake of milk would increase IgG antibodies complexed with milk and when transported across the placenta could reduce the risk of CMA (23). Balancing the Th-1 and Th-2 responses after delivery is affected by a rapidly diversifying ecological balance of organisms (microbiome) on the infant's skin, in the respiratory and gastrointestinal tracts. A healthy microbiome (Eubiosis) is achieved by $2-3$ years of age and is facilitated by pre-biotic oligosaccharides in human breast milk and a diverse healthy diet during weaning $(24,25)$. Moreover, a mutually beneficial 
(symbiotic) relationship exists with our microbiome contributing to digestion, absorption, protection against pathogens, healthsustaining immunological and metabolic responses (25).

The allergic march has conventionally presented a sequence commencing with food allergy; in which atopic dermatitis (AD) may be succeeded by asthma and hay fever though allergic rhinitis is more likely to precede asthma. This pre-supposes that the sequence of allergic diseases are manifestations of the same underlying pathophysiology suggesting that one condition leads inexorably to another. However, the gene/environment interactions of each condition are different (26). Allergic sensitization may occur without any clinical manifestations, while $\mathrm{AD}$, asthma and rhinitis can exist separately. Nevertheless, there are some mechanistic explanations for progression through the march for a proportion of subjects. The genetic basis for $\mathrm{AD}$ is a defect in skin barrier function of which the best studied is polymorphisms in the gene coding for filaggrin. Defects in this protein lead to increased fluid loss from the epidermis and increased susceptibility to inflammation induced by irritants and micro-organisms, thereby leading to AD (27). The dysfunctional skin barrier is more permeable such that food and inhalant allergens can penetrate through to the dermis where antigen presenting cells can pick up allergen and migrate to regional lymphoid accumulations for sensitization to occur (28). The sequence of the march is, therefore, incorrect with food allergy more likely to be a consequence of the gene defect contributing to $\mathrm{AD}$ and more likely to follow rather than precede it.
Given the ubiquity of cow milk in domestic environments, skin contact is inevitable and CMA most likely evolves by this route and certainly is most commonly seen in infants with co-existent $\mathrm{AD}$. Inhalant allergy can also occur by the same route and filaggrin gene polymorphisms are associated with an increased risk of allergic rhinitis and asthma following AD (29). It is therefore, not surprising that allergy to foods, particularly with co-existent $\mathrm{AD}$, is sometimes followed by the development of asthma. While the progression from $\mathrm{AD}$ associated with egg allergy to asthma has consistently been demonstrated, there is less evidence concerning milk allergy $(28,30)$. The allergic march is therefore much more complex, and it may be better to view it as a stop/start dance, such as a tango (31).

\section{PRIMARY PREVENTION OF CMA}

Understanding the mechanisms and developing strategies for the prevention of food allergy including CMA is important to curb the increasing incidence of cow's milk protein allergy (Figure 1) $(12,13)$. Family history of allergy-associated diseases is the most important risk factor for allergy manifestations in the offspring. Primary prevention strategies could be applied in high-risk infants defined as those with a first-degree relative with a history of allergy $(32,33)$. This section will discuss several potential interventions to prevent the occurrence of CMA in later life.

\section{SENSITIZATION}

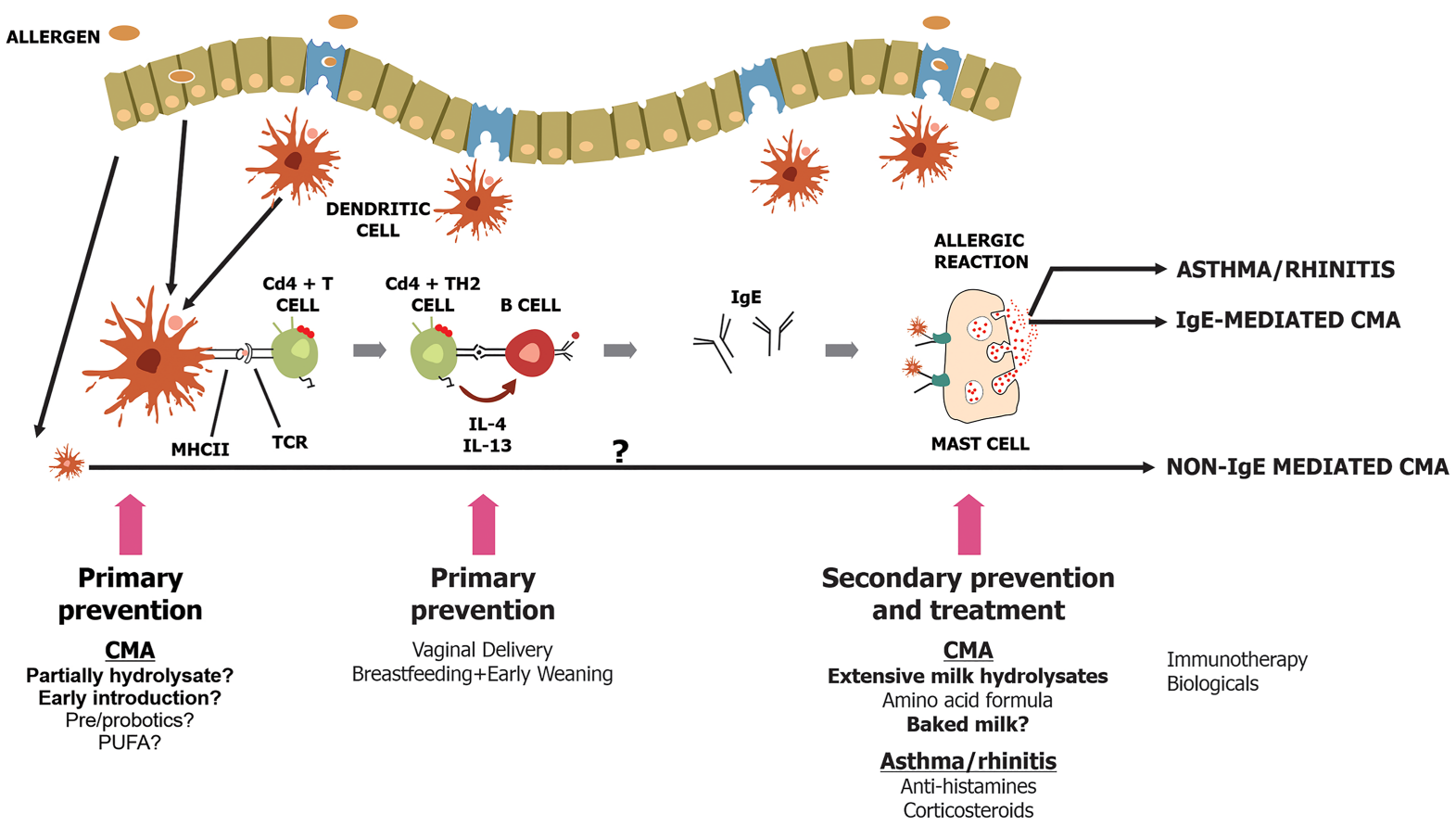

FIGURE 1 | Schematic diagram on primary, secondary and tertiary prevention [adapted from (12)]. 


\section{Maternal Diet in Pregnancy and Lactation}

There is little data available to support the manipulation of the maternal diet during pregnancy or lactation to prevent CMA (34). Kramer and Kakuma conducted a Cochrane Systematic Review which included evidence from five trials, and the overall conclusion was that antigen avoidance during pregnancy and lactation was unlikely to reduce the risk of atopy occurring in their children (35). Several studies showed no reduction in CMA or egg allergy in infants whose mothers were avoiding the respective foods during pregnancy and lactation $(36,37)$. This is because it is not a linear relationship between exposure levels and allergy risk. It is a bell-shaped curve in which high exposure induces tolerance and very low exposures are not sufficient to trigger a response, while the mid-range level of exposure leads to higher risks of sensitization. Avoidance usually just shifts the bell-shaped curve to the left resulting in no overall change in the population with equal numbers being moved from high dose tolerance to mid-range sensitization and equal numbers from the mid-range to the low dose without sensitization. Trials of maternal high-dose exposures to common food allergens during pregnancy are required. Animal models suggest this approach could confer benefits. Oral ovalbumin in pregnancy can induce tolerance in infant BALBc mice and the protective effect was abrogated by inhibition of placental IgG transfer or infant memory T-cell IFN- $\gamma$ production (38). A study of 1277 mother-child pairs from the USA unselected pre-birth cohort showed that a high peanut intake in the 1st trimester reduced the risk of developing peanut allergy to 0.53 (0.30-0.94). High milk intake in the 1st trimester reduced the odds ratio for asthma 0.83 (0.69-0.99) and rhinitis $0.85(0.74-0.97)$ while a high wheat intake in the 2 nd trimester reduced the odds ratio for eczema 0.64 (0.46-0.90) (39).

\section{Breastfeeding}

Breastfeeding is an important factor that can lower food allergy development through several mechanisms (Figure 2). These include potentially anti-allergic immune properties in the milk, and the possibility that prolonged breastfeeding may delay allergen introduction, but also the presence of antibodies within breast milk may combine with food antigens to induce tolerance (42). In animal models, it has been shown that antigenimmunoglobulin (IgG) immune complexes from sensitized dams were transferred to the newborn through the neonatal Fc receptor resulting in the induction of antigen-specific FoxP3(+) CD25(+) regulatory T cells (43). The transfer of these immune complexes could induce tolerance and support the development of primary prevention of CMA $(23,44)$.

Recent experimental data reported the role of short-chain fatty acids (SCFA), butyrate in particular, which enhance oral tolerance in the off-spring $(45,46)$. Likewise, human milk oligosaccharides (HMOs) in breast milk and prebiotics (galactooligosacharides) or a specific HMO (like 2-fucosyllactose) included into infant nutrition can induce the production of SCFAs suggesting that they may play a role in the primary prevention of CMA (47).

Breastmilk also contains various bioactive components such as immune active peptides (cytokines), fatty acids, HMOs, microbial contents and micronutrients which have been proven to modulate the immune system (41). One of the longest cohort studies, the PROBIT trial, has recently reported that breastfed infants had a lower risk of developing flexural

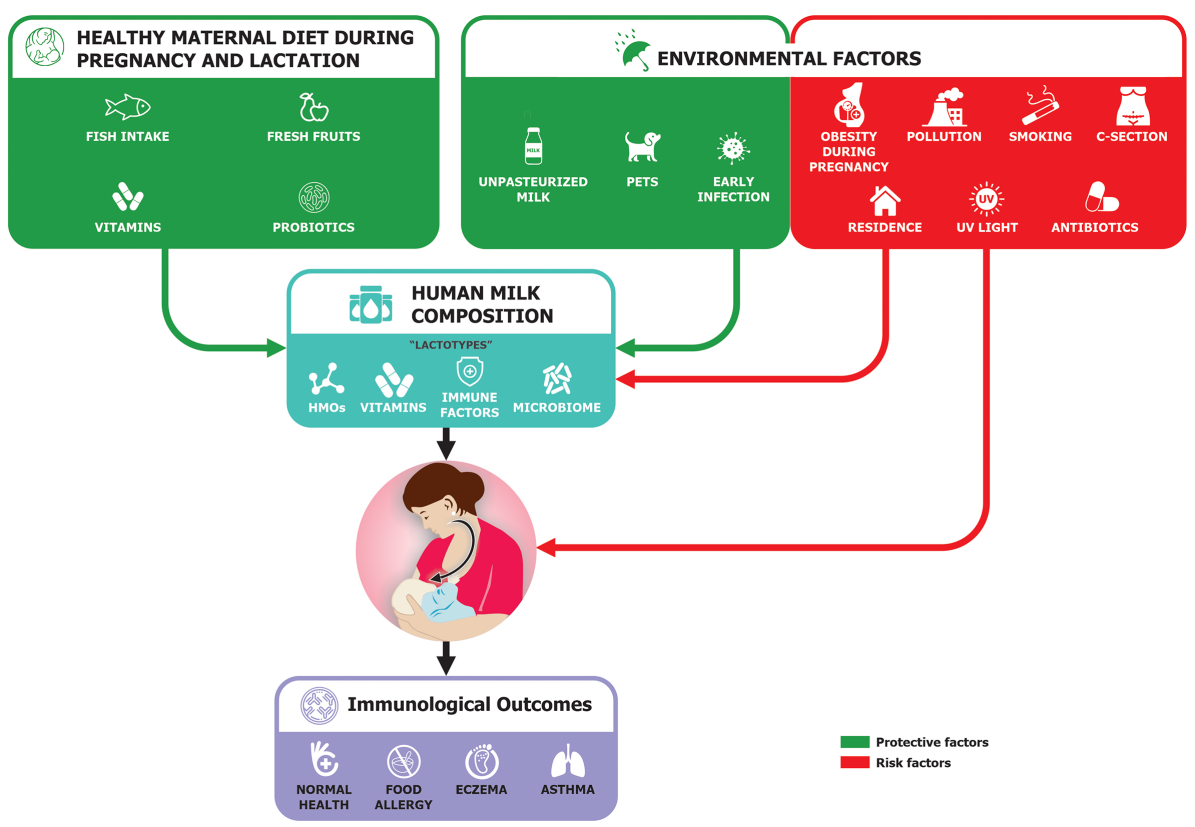

FIGURE 2 | Possible maternal influence on immunological outcomes in child [adapted from Verhasselt (40) and Munblit et al. (41)]. 
dermatitis at 18 years of age. However, there was no effect on lung function, the incidence of CMA and asthma (48).

\section{(Partially) Hydrolyzed Formulae for Non-Exclusively Breastfed Infants}

Partially hydrolyzed formulae (pHF) generally contain peptides with molecular weights around $<5,000 \mathrm{Da}(49)$. The partial hydrolysis removes part of the sensitizing epitopes which reduces the allergenicity of the proteins and their ability to induce sensitization, while retaining sufficient size of peptides to stimulate the induction of oral tolerance $(50,51)$.

The role of partially hydrolyzed formulae (pHF) for primary prevention of CMA has been long debated (52). The longest, largest, longitudinal studies on pHF, the German Infant Nutritional Intervention Study (GINI study) which started in early 2000 showed that whey pHF was significantly associated with reduction of $\mathrm{AD}$ manifestations up to the age of 15 years old (53-57) and reduced the risk for asthma and other respiratory symptoms (58). However, a more recent study with pHF enriched with pre-biotic oligosaccharides did not show any preventive effect (59).

Furthermore, there is no consensus with regards to early exposure to intact CMP in the first few weeks of life and the risk of CMA in later life. A large observational cohort study showed that delayed introduction of cow's milk products in the infants' diet was associated with an increased risk of developing atopy at 2 years of age, especially $\mathrm{AD}(60)$. A prospective study assessing the risk factors for CMA found early (within 14 days of life) introduction of CMP formulae presented lower rates of IgEmediated CMA compared to those with late consumption at 105194 days of life $[0.05 \%$ versus $1.75 \%$ respectively $(\mathrm{p}<0.001)]$ (61). A recent study showed that early continuous exposure to CMP may reduce the risk of CMA; while an introduction to CMP formulae during the first 3 days of life followed by complete CMP avoidance until the child is weaned may have the opposite effect (62). The difference in outcome may be influenced by the family history.

From a health economic perspective, a cohort using a Markov model simulating the $\mathrm{AD}$ incidence and burden from birth to age 6 years in a target population fed with whey pHF vs CMF, suggested that feeding a high-risk infant whey pHF resulted in a $14 \%$ reduction in $\mathrm{AD}$ risk (95\% CI, 3\%-23\%) and a per-child net saving of MYR 1,113 (US \$352) (95\% CI, MYR 317-1,884) favoring whey $\mathrm{pHF}$ (63).

The European Academy of Allergy and Clinical Immunology (EACCI) recommends exclusive breastfeeding in the first few weeks of life. If needed, a hydrolyzed milk formulae could be recommended under medical guidance to reduce the risk of $\mathrm{AD}$ depending on the clinical, economic and cultural factors (64). This recommendation follows the latest Cochrane review in 2018 on pHF and allergy prevention which states that there is no evidence to support feeding with $\mathrm{pHF}$ for the prevention of allergic diseases (65). The change in recommendation could be most probably driven by the negative results reported in the recent studies (59).

\section{Timing of Weaning Food Introduction}

The concept of oral tolerance is well-documented from previous work showing how early and regular oral exposure induces clinical tolerance and altered immunological responses to food allergens $(32,66)$. Further research in humans has also shown that early ingestion of food allergens can lead to oral tolerance while skin contact before tolerance has been achieved, particularly in the presence of inflammation, epidermal barrier defects and $\mathrm{AD}$, leads to sensitization (32). The evidence supporting the role of early introduction of potential allergens in the development of oral tolerance to prevent food allergy is mounting. Although there are still questions as to the timing and also which allergens can be introduced safely and with effect, a shift from recommending avoidance of common food allergens to early consumption strategies to prevent the development of food allergy is occurring. The LEAP study and EAT study reported the benefit of early complementary feeding with egg and peanut allergy, but an equivocal effect for milk. It was not clear whether early introduction of milk and other allergens was useful to reduce the risk of allergy due to difficulty in complying with the regimen in the study $(67,68)$. Furthermore, the EAT study also reported that the rates of non-IgE symptoms at any time point were equivalent between groups suggesting that the introduction of the study foods was associated with the reporting of these symptoms regardless of when they were introduced. Specifically, $11.9 \%$ of participants in the early introduction group reported non-IgE type symptoms to one or more of the early introduction weaning (69) foods at any point (4-12 months) compared to $9.6 \%$ of the standard introduction group $(\mathrm{p}=0.20)$. However, this effect on non-IgE mediated allergy may indicate that there was not enough exposure to alter immune responses or were due to other causes.

AAP in 2019 recommended introducing peanut between $4-12$ months in countries with a high prevalence of peanut allergy and well-cooked egg between $6-8$ months (70). This is further emphasized in the recent EAACI guidelines which stated that in countries where egg allergy is an issue, providing well-cooked egg twice a week between the age of 4-6 months can be recommended (64). There is no reason for delayed introduction $>12$ months nor for an early introduction $<4$ months. Experts recommend consideration of local data, dietary practices and family preferences and assessment of the child's and family atopic status when introducing early foods during weaning to reduce the incidence of food allergy.

In addition to weaning foods, timely introduction to intact cow's milk in non-high risk infants perhaps around 4-6 months is likely to be of value $(69,71)$

\section{Environmental Factors}

Interestingly, epidemiological evidence points to the role of unprocessed farm milk as protective in the development of asthma and allergy. In several large epidemiological studies, the consumption of unprocessed farm milk and exposure to the farming environment were associated with a lower incidence of asthma and allergy $(72,73)$. To date two studies have tested the exposure of cow's milk allergic children after weaning period to 
raw milk as compared to regular shop milk, and in both these studies raw milk led to fewer medical complaints related to asthma and allergies $(74,75)$. Collectively these findings suggest that unprocessed milk contains factors that can prevent the development of clinical allergy due to the influence of cow milk's microbiome and/or other immune active constituents.

\section{Topical Emollients}

As a compromised skin barrier and the presence of dermatitis predisposes to percutaneous sensitization risk to food antigens, there is the possibility that good skin care aiming at active AD control may decrease allergen sensitization and the subsequent allergy march $(76)$. Both the ecological perspective $(77,78)$ and basic cutaneous biology $(79,80)$ have suggested that epidermal barrier dysfunction is a key initiator to the development of AD. The use of emollients in reducing eczema is still inconclusive. Some studies show a reduction in eczema development with no reduction of food sensitization. However, recent evidence reports that the use of emollients from birth may not be protective against the onset of AD in infants and young children (81).

\section{LCPUFAs}

Maternal diets high in omega-3 long-chain polyunsaturated fatty acids (LCPUFA) are thought to have a protective effect against the development of allergies in the newborn (82). Supplementation with docosahexaenoic acid and eicosapentaenoic acid during pregnancy has been shown to increase LCPUFA concentrations in breast milk (83). A large randomized clinical trial of maternal fish oil supplementation (500 $\mathrm{mg}$ of docosahexaenoic acid and $150 \mathrm{mg}$ of eicosapentaenoic acid) during pregnancy demonstrated a significant decrease in cord blood concentrations of Th-2 cytokines (IL-4 and IL-13) as well as increased levels of oral tolerance-inducing TGF-beta (84). However, this study showed no effect on clinical outcomes. Palmer et al. assessed the effect of high-dose fish oil supplementation $(800 \mathrm{mg}$ ) in high-risk infants (with a positive family history of atopy) on infantile eczema and food sensitization at 12 months of age. Those receiving the fish oil supplementation had significantly lower rates of atopic eczema and egg sensitization. High intake of omega 3 LCPUFA via fish oil supplementation or high intake of oily fish during pregnancy and after birth seems to reduce the risk of $\mathrm{AD}$ and food sensitization to common allergens and asthma but not specifically to CMP (85, 86). This suggests the influence of dose and other risk factors can impact specific allergic outcomes and not just a single interventional factor.

\section{Modulation of the Gut Microbiome With Prebiotics and Probiotics}

The latest Cochrane review in 2013 reported a potential benefit of prebiotics during infancy in the prevention of $\mathrm{AD}$, but no conclusive evidence was found regarding the prevention of other allergic diseases or food allergies (87).

Human Milk Oligosaccharides (HMO) are complex, nondigestible oligosaccharides with prebiotic properties in breast milk which provide a specialized substrate for Bifidobacteria and enhance an ecological balance associated with eubiosis directly or indirectly via SCFA production (88). Over the past decade, several manufactured prebiotics have been added to infant formulas, including plant-based long-chain fructo-oligosaccharides (FOS) and short chain galacto-oligosaccharides (GOS). GOS and FOS have been shown to increase counts of fecal Bifidobacteria in formula-fed infants $(89,90)$. A randomized trial of a GOS/FOS with 9:1 ratio supplemented pHF investigated the effect on $\mathrm{AD}$ in formula-fed infants during the first 6 months of life. In that study, the GOS/FOS group had significantly lower rates of AD compared to the placebo group, although severity was similar for both treatment arms (91). A more recent European multi-center randomized controlled trial assessed the effect of neutral oligosaccharides (GOS/FOS) and pectin-derived acidic oligosaccharides in a standard infant formulae in healthy, lowrisk infants from 8 weeks to 12 months (92). These prebiotics reduced the incidence of $\mathrm{AD}$ by $44 \%$ at 12 months with no effect on disease severity. However in a more recent study, there was no effect of GOS/FOS on AD incidence, although immunological differences and effects on the gut microbiome resembling those receiving human milk was noted in those receiving GOS/FOS supplemented formula compared with standard formula were noted (59). The dynamics of the evolving microbiome in these infants were different in those who developed $\mathrm{AD}$ suggesting a further influence of GOS/FOS on the microbiome in the development of oral tolerance as compared to intact protein milk formula $(59,93)$.

HMOs in breast milk provide the substrate for specific microbes and significantly influence early microbial gut colonization $(94,95)$. In preclinical studies, HMO has been shown to attenuate allergic responses in cow's milk-sensitized mice (96). The role of HMO in the prevention and treatment of CMA represents a promising area for future research (96-98).

An inverse association between microbial exposure in early life and allergy was suggested by the hygiene hypothesis (99). Since then, there has been increasing interest in diet supplementation with live bacterial cultures (Lactobacillus rhamnosus GG, Lactobacillus acidophilus, Lactobacillus reuteri, and mixed cultures). They have protective gastrointestinal effects modulating immune responses and contribute to the regulation of theTh1/Th2 ratio and stimulation of the regulatory cytokine IL-10. A meta-analysis of randomized controlled clinical trials investigating the use of probiotics in infants for primary prevention of allergies found a small reduction in $\mathrm{AD}$ in infants, but insufficient evidence for a general recommendation of probiotic supplementation for prevention of allergic disease or food hypersensitivity (100).

The World Allergy Organization and Mc Master University Guidelines for Allergic Disease Prevention (GLAD-P) panel of experts indicated a lack of robust evidence confirming the effectiveness of strain-specific probiotics in a group of pregnant or breastfeeding women, or infants at a high risk of atopy on prevention of food allergy (101). However, its effect on reducing the risk of $\mathrm{AD}$ has been reported in a meta-analysis (100) and in infants (102). No studies have reported the effect of supplementing strain-specific probiotics during pregnancy or early life in primary prevention of CMA $(103,104)$. However, the effect of mixed strains of probiotics, or synbiotics (a mixture 
of pre- and pro-biotics) to achieve greater microbiota diversity has been shown to reduce the risk of necrotizing enterocolitis in premature infants. The same might be true for the primary prevention of food allergy and is worthy of further investigation.

\section{SECONDARY PREVENTION AND MANAGEMENT OF CMA}

Preventing disease progression from mild or moderate symptoms to severe symptoms or another allergy phenotype in children with CMA is considered as secondary prevention and management of CMA (33).

\section{Extensively Hydrolyzed Formulae}

Whey- or casein-based eHF are considered the first-line management of formula-fed infants with $\operatorname{CMA}(13,17,49,105)$. These formulas contain short cow's milk peptides that are produced via enzymatic breakdown and ultrafiltration of intact cow's milk proteins. There are significant differences in the molecular weights and profiles of peptides in eHF $(106,107)$. A task force of the European Academy of Allergy and Clinical Immunology (EAACI) has therefore called for stricter standards for the definition of eHF marketed in Europe, including preclinical testing, quality assurance, and labelling requirements (104). In 2016, DRACMA updated their recommendation to include the provision of rice hydrolysate in the first-line management in countries where this formula is available (108).

\section{Amino Acid-Based Formulae (AAF)}

AAF is a synthetic, nutritionally complete, cow's milk antigenfree formulae containing free amino acids, which is used in the treatment of infants with severe CMA. Its cost-effectiveness in clinical practice is dependent on the healthcare system and cost of formula in a particular country $(109,110)$. AAF is therefore not a first-line treatment but recommended for infants who have failed treatment with eHF (17), as well as infants with very severe symptoms such as cow's milk anaphylaxis (111) or multiple food intolerances (112). As tolerance development is thought to be an antigen-driven process, the use of AAF is unlikely to promote tolerance development (113) although a recent study showed that supplementing AAF with synbiotics improved the gut microbiota in non-IgE mediated allergic infants (114). The use of AAF for more than 6 months in children was recently reported to have the potential adverse effect of causing hypophosphatemic bone disease especially among those with complex GI conditions (115-119). These studies also reported restoration of calcium and phosphorus homeostasis following a formula change to eHF. In addition, data from healthy volunteers in an acute setting did not indicate differences in calcium and phosphorus bioavailability from various types of AAF even if combined with an acidsuppressant medication (120).

\section{Partially Hydrolyzed Formulae (pHF)}

It may be prudent to consider the role of $\mathrm{pHF}$ in the management of CMA under certain conditions, such as mild cases of CMA or weaning from eHF before introducing intact cow's milk protein.
Given the highly controlled manufacturing process in the production of $\mathrm{pHF}$, they provide potentially a safer alternative compared to using either baked milk, or small doses of heated milk $(3 \mathrm{ml})$, both of which were shown to be successful in enhancing tolerance to the unheated CMP, as compared to allergen avoidance regimens $(121,122)$. Around $72 \%$ (out of 55 tested subjects) of non-IgE allergic children were able to tolerate $\mathrm{pHF}$ in an open food challenge without any adverse events (123). In another recent study, Inuo et al. also demonstrated an increased tolerance in allergic children towards higher quantities of pHF compared to intact $\mathrm{CM}$ and found no significant differences between the $\mathrm{pHF}$ and eHF in the rate of tolerance or induction of allergic symptoms (51). It has been hypothesized that partially hydrolyzed proteins (whey- or casein-derived peptides of various molecular weights) will result in better oral tolerance induction in a setting of immature gastrointestinal and immune systems, compared to intact CMP.

\section{Modulation of Gut Microbiome With Prebiotics and Probiotics}

In addition to the previously mentioned FOS and GOS as prebiotics, a recent publication reported the hypoallergenic effect of eHF supplemented with two human milk oligosaccharides (HMO), namely 2'fucosyl-lactose (2'FL) and lacto-N-neotetraose (LNnT) as compared to eHF only among children with CMA. The study reported that the eHF supplemented with HMOs is safely tolerated by infants with CMA (124).

Provision of strain specific probiotics, especially Lactobacillus GG (LGG) in management of CMA and induction of oral tolerance have been reported in several studies (125). eHF with LGG has been reported to have the absolute risk difference for the occurrence of at least 1 allergic manifestation over 36 months of -0.23 (95\% CI -0.36 to $-0.10 ; \mathrm{p}<0.001)$ and the absolute risk difference for the acquisition of cow's milk tolerance was 0.20 (95\% CI 0.05-0.35; $\mathrm{p}<0.01)$ at 12 months, 0.24 (95\% CI $0.08-0.41 ; \mathrm{p}<0.01)$ at 24 months, and 0.27 (95\% CI $0.11-0.43$; p < 0.001) at 36 months as compared to eHF without LGG. The addition of LGG has also significantly increased fecal butyrate levels which have been reported to potentially facilitate oral tolerance induction $(45,126)$.

\section{STEP-DOWN APPROACH TO BUILD EARLY TOLERANCE IN RE-INTRODUCING INTACT COW'S MILK PROTEIN}

By providing the $\mathrm{pHF}$ in between AAF or eHF and full cow's milk as part of a step-down approach in the management of CMA, it is postulated that the children might achieve tolerance to CMP sooner (49). There are differences between eHFs in the degree of hydrolysis, which affects the distribution of peptide size (127).

Common casein-based eHF generally have a high degree of hydrolysis (eg $37 \%$ ) and $80 \%$ of peptide less than $500 \mathrm{Da}, 10 \%$ of peptides between $500-1000 \mathrm{Da}$ and $10 \%$ of peptides larger than $1 \mathrm{kDA}$ (127). On the other hand, the majority of eHF whey-based formulas have a lower degree of hydrolysis (e.g. 22\%) resulting in a smaller percentage of peptides between $500 \mathrm{Da}-1 \mathrm{kDA}$ and 
remaining $40 \%>1 \mathrm{kDA}$ (127). We hypothesize that having two different eHFs with different degrees of hydrolysis could be useful as an intermediate step between extensive hydrolyzed, in general, and partially hydrolyzed protein. For the ease of differentiation, we will refer to the hydrolysates with has a lower degrees of hydrolysis as Intermediate Hydrolyzed Formula (iHF).

In allergen immunotherapy, tolerance to inhalant allergens is induced by injecting allergic individuals with low doses of allergens, to enhance non-IgE antibodies (most notably IgG4) and enhance the regulatory T-cell generation of TGF-b and IL-10 (128). By analogy, hydrolysates that do not retain IgE-binding epitopes (>30 aa) but retain CD4+ T cell epitopes (12-18 aa) may modulate $\mathrm{T}$ cell responses to the allergen in the absence of inducing IgE-mediated allergic responses (129).

In an in-vitro mode, different lengths of peptides have been shown to influence the local and systemic immune response especially in strengthening the gut epithelial barrier via increasing the regulatory cytokines (ie IL-10) and decreasing pro-inflammatory markers such as cyclo-oxygenase2 (COX-2) and IL-8. Peptides also have been shown to modulate immune responses via direct interaction with Toll-like receptors (TLR) which are responsible for interaction between pathogen and the gut mucosa but are also suggested to have an immunemodulatory role in allergic inflammation (130). The TLR activating capacity of whey hydrolysates decreased with the increasing level of hydrolysis (131).

The step-down approach for children with CMA using a hydrolysate milk ladder incorporating $\mathrm{pHF}$ as a bridge between extensively (eHF) and the intact CM formulae is currently implemented in Greece under careful monitoring. It is suggested that one more step is added from casein to whey based eHF (iHF) and then to pHF formula, after stringent evaluation of the individual's clinical history and skin prick test' wheal size to each hydrolysate formulae (Figure 3). A clinically monitored oral challenge to the respective formulae is conducted before allowing consumption at home.
There are several so-called milk ladders from baked to nonbaked food that is currently recommended in Europe to slowly reintroduce cows' milk proteins into an infants' diet when it is assumed that the allergy is resolving. An example commences with a malted milk biscuit followed if tolerated successively by cheesy breadsticks, custard, a teaspoon of yoghurt, cheese, and finally pasteurized milk (132). The issue with milk ladders is that the levels of CMP in each step are uncharacterized and likely variable dependent on the degree of heating and/or processing and are based on observational rather than controlled studies.

Ideally, formulas with various degrees of hydrolysis are needed in a hydrolysate milk ladder. In that way, the introduction of peptide to protein fragments can be more controlled and will eliminate the presence of several biases such as the presence of other potential allergens. However, considering the cost of such formulas and the ease of baked-milk food during the weaning period, this step-wise proposal using various degree of hydrolysate needs to be proven in a clinical setting to be cost/effective as compared to current milk ladders before recommending it for routine practice. Before robust clinical evidence is available, this step-wise proposal should be implemented in a clinical setting with stringent medical guidance; and in selected cases such as among children with confirmed Ig-E mediated CMA.

Around $50 \%$ of infants receiving $\mathrm{eHF}$ will have developed tolerance by the age of 12 months (133). With the above-mentioned step-down proposal, it is hypothesized that there could be a possibility for an increase of more than $50 \%$ of children who would gain tolerance at 12 months or shorter duration than 12 months for developing tolerance. These outcomes will have a significant impact on reducing the health and economic burden of the affected families.

Tolerance will be determined by conducting oral food challenges as the preferred diagnostic standard. In principle, food challenges include seven doses for both the active and the placebo arm of the challenge (in the case of DBPCFC) as suggested by previous recommendations and the EuroPrevall and iFAAM projects $(4,134)$.

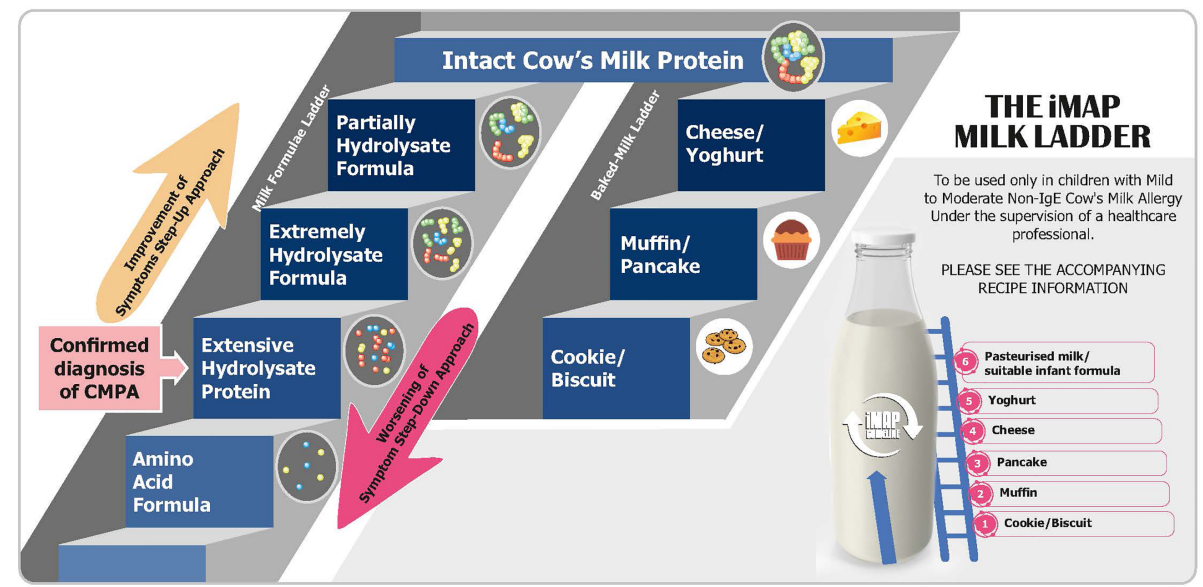

FIGURE 3 | Milk formulae and baked-milk ladder step-down and step-up to support early tolerance in management of CMPA. 
Other mammalian-based formulas (e.g. sheep, goat) will not be tolerated by the majority of subjects with CMA. Soy-based formulas are not recommended for use under the age of 6 months of age in many European and American Allergy guidelines, and other plant-based milk (e.g. rice, almond, oat) could be nutritionally inadequate (135).

\section{UNMET NEED AND FUTURE RESEARCH}

Several studies on migrating families revealed a big discrepancy in the prevalence of food allergy if there is a mismatch between the pre-conception, antenatal and postnatal environment. For example, if the mother conceives and gives birth in a new country, the baby has a higher risk of food allergy and $\mathrm{AD}$ compared to babies who were born in the country of maternal origin $(136,137)$. This amply illustrates that environmental factors rather than genetics had contributed to the increasing prevalence of food allergy. As such, there is therefore a greater chance that environmental modification will favorably impact on allergy risks in the future. Based on the evidence, we believe that a multi-faceted approach to prevention should be submitted to controlled clinical trials. These should be employed during preconception and pregnancy with an optimized diverse diet and no food allergen avoidance, no smoking, antibiotic avoidance if possible, and avoidance of a caesarean section delivery. If either of the latter is not possible then administration of pre/pro/ synbiotics to the mother during pregnancy is indicated. Postnatally the ideal is breast feeding but if not possible, whole milk formula supplemented with pre-and probiotics. Rapid weaning onto the common allergenic foods beyond 4 months of age, with a particular focus on peanut and egg is proposed for both breast and bottle-fed infants. Preferably, weaning should proceed while breast feeding is continued.

Intervention during pregnancy or pre-pregnancy remains the best option to prevent CMA in the offspring as there is evidence that the high levels of specific IgG to a particular allergen at birth reduces the risk of allergy. For example, a study of ryegrass immunotherapy during pregnancy showed high levels of a specific IgG to ryegrass and reduced risk of ryegrass allergy compared to those born to mothers who are allergic and didn't receive immunotherapy during pregnancy (138).

For postnatal intervention, if the mother is a high milk drinker during pregnancy, then it would seem rational to give milk proteins postnatally early because having IgG milk protein complex transfer across the placenta should be matched with early tolerance induction before sensitization can occur via nonGI tract exposure. This requires controlled trials to establish if it is effective. On the other hand, if the mother has a very low milk intake, it may not be appropriate to suddenly give milk proteins post-natally. High milk intake during pregnancy is associated with a reduced risk of asthma and allergic rhinitis at 8 years of age (39). There could be some correlation between the low maternal milk intake and the high incidence of CMA in offspring. Therefore, there is likely to be no one-size-fits-all approach to prevent CMA, and clinical judgment may be based on maternal milk exposure during pregnancy. All the suggested strategies above require controlled clinical trials before being employed as routine practice.

There is a need to conduct a controlled, prospective follow-up study in babies with $\mathrm{AD}$ and appropriately confirm CMA to evaluate the impact of early introduction of a milk ladder using progressively less hydrolyzed milk formulae on tolerance development to CM and the subsequent development of other allergic disorders later in childhood compared to the current standard of waiting for 6-12 months for re-challenge $(49,69,71)$. If this approach is successful in inducing the early development of tolerance to cow's milk protein, it could have considerable health economic benefits.

\section{CONCLUSION}

Increased incidence of food allergy, including CMA, among infants and young children, has been observed over the last decade $(3,139)$. Its primary prevention should include having food diversity during pregnancy to ensure the transfer of IgG-allergen complexes prenatally (and by breast milk postnatally) to provide early tolerizing exposure to the fetus. In addition, continued exposure to milk among milk-drinking breastfeeding mothers postnatally should be continued. For non-breastfed infants at risk to developing CMA, partially hydrolyzed formulae with proven efficacy may provide health-economic benefit among high-risk infants with a family history of allergy $(140,141)$ but further trials are required.

Secondary prevention in the management of CMA should focus on the use of eHF mainly due to its immune-modulating capabilities to induce tolerance as compared to AAF. We hypothesize that the introduction of hydrolysates with various degrees of hydrolysis may help in building faster oral tolerance and thus can be considered in a milk formula ladder, in addition to clinically proven pre- and probiotics. All of these proposals require further controlled trials before they can be recommended for routine practice.

\section{AUTHOR CONTRIBUTIONS}

All authors were involved in setting the concept and objective for the review. BZ-O contributed the first draft which was then further developed by LM, JN, UK, and JW based on the meeting report and latest publications. All authors participated in the development of the final manuscript by providing comments and suggestions. All authors contributed to the article and approved the submitted version.

\section{FUNDING}

FrieslandCampina provided an educational grant to develop the 2 figures in the manuscripts to SovereignHealth, Singapore and funded the 2-day meeting. None of the authors received funding from FrieslandCampina to write the manuscript. 


\section{REFERENCES}

1. Kang SY, Song WJ, Cho SH, Chang YS. Time Trends of the Prevalence of Allergic Diseases in Korea: A Systematic Literature Review. Asia Pac Allergy (2018) 8(1):e8. doi: 10.5415/apallergy.2018.8.e8

2. Anandan C, Nurmatov U, van Schayck OC, Sheikh A. Is the Prevalence of Asthma Declining? Systematic Review of Epidemiological Studies. Allergy (2010) 65(2):152-67. doi: 10.1111/j.1398-9995.2009.02244.x

3. Li J, Ogorodova LM, Mahesh PA, Wang MH, Fedorova OS, Leung TF, et al. Comparative Study of Food Allergies in Children From China, India, and Russia: The EuroPrevall-INCO Surveys. J Allergy Clin Immunol In Pract (2020) 8(4):1349-58.e16. doi: 10.1016/j.jaip.2019.11.042

4. Roberts G, Allen K, Ballmer-Weber B, Clark A, Crevel R, Dunn Galvin A, et al. Identifying and Managing Patients At Risk of Severe Allergic Reactions to Food: Report From Two iFAAM Workshops. Clin Exp Allergy (2019) 49 (12):1558-66. doi: 10.1111/cea.13516

5. Wopereis H, Oozeer R, Knipping K, Belzer C, Knol J. The First Thousand Days - Intestinal Microbiology of Early Life: Establishing A Symbiosis. Pediatr Allergy Immunol (2014) 25(5):428-38. doi: 10.1111/pai.12232

6. Alduraywish SA, Lodge CJ, Campbell B, Allen KJ, Erbas B, Lowe AJ, et al. The March From Early Life Food Sensitization to Allergic Disease: A Systematic Review and Meta-Analyses of Birth Cohort Studies. Allergy (2016) 71(1):77-89. doi: 10.1111/all.12784

7. Du Toit G, Sampson HA, Plaut M, Burks AW, Akdis CA, Lack G. Food Allergy: Update On Prevention and Tolerance. J Allergy Clin Immunol (2018) 141(1):30-40. doi: 10.1016/j.jaci.2017.11.010

8. Schoemaker AA, Sprikkelman AB, Grimshaw KE, Roberts G, Grabenhenrich L, Rosenfeld L, et al. Incidence and Natural History of Challenge-Proven Cow's Milk Allergy in European Children-EuroPrevall Birth Cohort. Allergy (2015) 70(8):963-72. doi: 10.1111/all.12630

9. Flom JD, Sicherer SH. Epidemiology of Cow's Milk Allergy. Nutrients (2019) 11(5):1051. doi: 10.3390/nu11051051

10. Johansson SG, Bieber T, Dahl R, Friedmann PS, Lanier BQ, Lockey RF, et al. Revised Nomenclature for Allergy for Global Use: Report of the Nomenclature Review Committee of the World Allergy Organization, October 2003. J Allergy Clin Immunol (2004) 113(5):832-6. doi: 10.1016/j.jaci.2003.12.591

11. Heyman MB. Lactose Intolerance in Infants, Children, and Adolescents. Pediatrics (2006) 118(3):1279-86. doi: 10.1542/peds.2006-1721

12. van Neerven RJJ, Savelkoul HFJ. The Two Faces of Cow's Milk and Allergy: Induction of Cow's Milk Allergy vs. Prevention of Asthma. Nutrients (2019) 11(8):1945. doi: 10.3390/nu11081945

13. Vandenplas Y. Prevention and Management of Cow's Milk Allergy in NonExclusively Breastfed Infants. Nutrients (2017) 9(7):15. doi: 10.3390/ nu9070731

14. Lyles JL, Martin LJ, Shoda T, Collins MH, Trimarchi MP, He H, et al. Very Early Onset Eosinophilic Esophagitis is Common, Responds to Standard Therapy, and Demonstrates Enrichment for CAPN14 Genetic Variants. J Allergy Clin Immunol (2021) 147(1):244-54.e6. doi: 10.1016/j.jaci.2020.10.017

15. Perkin MR, Logan K, Tseng A, Raji B, Ayis S, Peacock J, et al. Randomized Trial of Introduction of Allergenic Foods in Breast-Fed Infants. N Engl J Med (2016) 374(18):1733-43. doi: 10.1056/NEJMoa1514210

16. Munblit D, Perkin MR, Palmer DJ, Allen KJ, Boyle RJ. Assessment of Evidence About Common Infant Symptoms and Cow's Milk Allergy. JAMA Pediatr (2020) 174(6):599-608. doi: 10.1001/jamapediatrics.2020.0153

17. Meyer R, Groetch M, Venter C. When Should Infants With Cow's Milk Protein Allergy Use an Amino Acid Formula? A Practical Guide. J Allergy Clin Immunol In Pract (2018) 6(2):383-99. doi: 10.1016/j.jaip.2017.09.003

18. Groetch M, Baker MG, Durban R, Meyer R, Venter C, Muraro A. The Practical Dietary Management of Food Protein-Induced Enterocolitis Syndrome. Ann Allergy Asthma Immunol (2021) S1081-1206(21):00184-8. doi: 10.1016/j.anai.2021.03.007

19. Bollinger ME, Dahlquist LM, Mudd K, Sonntag C, Dillinger L, McKenna K. The Impact of Food Allergy on the Daily Activities of Children and Their Families. Ann Allergy Asthma Immunol (2006) 96(3):415-21. doi: 10.1016/ S1081-1206(10)60908-8

20. Gupta R, Holdford D, Bilaver L, Dyer A, Holl JL, Meltzer D. The Economic Impact of Childhood Food Allergy in the United States. JAMA Pediatr (2013) 167(11):1026-31. doi: 10.1001/jamapediatrics.2013.2376
21. Antolin-Amerigo D, Manso L, Caminati M, de la Hoz Caballer B, Cerecedo I, Muriel A, et al. Quality of Life in Patients With Food Allergy. Clin Mol Allergy (2016) 14:4. doi: 10.1186/s12948-016-0041-4

22. Warner JO. The Early Life Origins of Asthma and Related Allergic Disorders. Arch Dis Child (2004) 89(2):97-102. doi: 10.1136/adc.2002.013029

23. Adel-Patient K, Bernard H, Fenaille F, Hazebrouck S, Junot C, Verhasselt V. Prevention of Allergy to a Major Cow's Milk Allergen by Breastfeeding in Mice Depends on Maternal Immune Status and Oral Exposure During Lactation. Front Immunol (2020) 11(1545):731. doi: 10.3389/fimmu.2020.01545

24. Dore J, Blottiere H. The Influence of Diet on the Gut Microbiota and its Consequences for Health. Curr Opin Biotechnol (2015) 32:195-9. doi: 10.1016/j.copbio.2015.01.002

25. van den Elsen LWJ, Garssen J, Burcelin R, Verhasselt V. Shaping the Gut Microbiota by Breastfeeding: The Gateway to Allergy Prevention? Front Pediatr (2019) 7:47. doi: 10.3389/fped.2019.00047

26. Custovic A, Custovic D, Kljajic-Bukvic B, Fontanella S, Haider S. Atopic Phenotypes and Their Implication in the Atopic March. Expert Rev Clin Immunol (2020) 16(9):873-81. doi: 10.1080/1744666X.2020.1816825

27. Dennin M, Lio PA. Filaggrin and Childhood Eczema. Arch Dis Child (2017) 102(12):1101-2. doi: 10.1136/archdischild-2017-313010

28. Warner JOChild ESGETotA. A Double-Blinded, Randomized, PlaceboControlled Trial Of Cetirizine In Preventing The Onset Of Asthma In Children With Atopic Dermatitis: 18 Months' Treatment And 18 Months Posttreatment Follow-Up. J Allergy Clin Immunol (2001) 108(6):929-37. doi: 10.1067/mai.2001.120015

29. McLean WH. Filaggrin Failure - From Ichthyosis Vulgaris to Atopic Eczema and Beyond. Br J Dermatol (2016) 175 Suppl 2:4-7. doi: 10.1111/bjd.14997

30. Caffarelli C, Garrubba M, Greco C, Mastrorilli C, Povesi Dascola C. Asthma and Food Allergy in Children: Is There a Connection or Interaction? Front Pediatr (2016) 4:34. doi: 10.3389/fped.2016.00034

31. Levin MEW JO. The Atopic Dance. Curr Allergy Clin Immunol (2017) 30:150-4.

32. Lack G. Update on Risk Factors for Food Allergy. J Allergy Clin Immunol (2012) 129(5):1187-97. doi: 10.1016/j.jaci.2012.02.036

33. Halken S. Prevention of Allergic Disease in Childhood: Clinical and Epidemiological Aspects of Primary and Secondary Allergy Prevention. Pediatr Allergy Immunol (2004) 15(Suppl 16):4-5, 9-32. doi: 10.1111/ j.1399-3038.2004.0148b.x

34. Venter C, Agostoni C, Arshad SH, Ben-Abdallah M, Du Toit G, Fleischer DM, et al. Dietary Factors During Pregnancy And Atopic Outcomes In Childhood: A Systematic Review From The European Academy Of Allergy And Clinical Immunology. Pediatr Allergy Immunol (2020) 31(8):889-912. doi: $10.1111 /$ pai.13303

35. Kramer MS, Kakuma R. Maternal Dietary Antigen Avoidance During Pregnancy or Lactation, or Both, for Preventing or Treating Atopic Disease in the Child. Cochrane Database Syst Rev (2012) 2012(9): Cd000133. doi: 10.1002/14651858.CD000133.pub3

36. Khakoo A, Lack G. Preventing Food Allergy. Curr Allergy Asthma Rep (2004) 4(1):36-42. doi: 10.1007/s11882-004-0041-1

37. Vance GH, Lewis SA, Grimshaw KE, Wood PJ, Briggs RA, Thornton CA, et al. Exposure of the Fetus and Infant to Hens' Egg Ovalbumin Via the Placenta and Breast Milk in Relation to Maternal Intake of Dietary Egg. Clin Exp Allergy (2005) 35(10):1318-26. doi: 10.1111/j.1365-2222.2005.02346.x

38. Polte T, Hansen G. Maternal Tolerance Achieved During Pregnancy is Transferred to the Offspring Via Breast Milk and Persistently Protects the Offspring From Allergic Asthma. Clin Exp Allergy (2008) 38(12):1950-8. doi: 10.1111/j.1365-2222.2008.03096.x

39. Bunyavanich S, Rifas-Shiman SL, Platts-Mills TA, Workman L, Sordillo JE, Camargo CAJr., et al. Peanut, Milk, and Wheat Intake During Pregnancy is Associated With Reduced Allergy and Asthma in Children. J Allergy Clin Immunol (2014) 133(5):1373-82. doi: 10.1016/j.jaci.2013.11.040

40. Verhasselt V. Oral Tolerance in Neonates: From Basics to Potential Prevention of Allergic Disease. Mucosal Immunol (2010) 3(4):326-33. doi: 10.1038/mi.2010.25

41. Munblit D, Peroni DG, Boix-Amorós A, Hsu PS, Van't Land B, Gay MCL, et al. Human Milk and Allergic Diseases: An Unsolved Puzzle. Nutrients (2017) 9(8):843. doi: 10.3390/nu9080894

42. du Toit G, Tsakok T, Lack S, Lack G. Prevention of Food Allergy. J Allergy Clin Immunol (2016) 137(4):998-1010. doi: 10.1016/j.jaci.2016.02.005 
43. Mosconi E, Rekima A, Seitz-Polski B, Kanda A, Fleury S, Tissandie E, et al. Breast Milk Immune Complexes Are Potent Inducers of Oral Tolerance in Neonates and Prevent Asthma Development. Mucosal Immunol (2010) 3 (5):461-74. doi: 10.1038/mi.2010.23

44. Ohsaki A, Venturelli N, Buccigrosso TM, Osganian SK, Lee J, Blumberg RS, et al. Maternal IgG Immune Complexes Induce Food Allergen-Specific Tolerance in Offspring. J Exp Med (2018) 215(1):91-113. doi: 10.1084/jem.20171163

45. Vonk MM, Blokhuis BRJ, Diks MAP, Wagenaar L, Smit JJ, Pieters RHH, et al. Butyrate Enhances Desensitization Induced by Oral Immunotherapy in Cow's Milk Allergic Mice. Mediators Inflammation (2019) 2019:9062537. doi: 10.1155/2019/9062537

46. Folkerts J, Redegeld F, Folkerts G, Blokhuis B, van den Berg MPM, de Bruijn MJW, et al. Butyrate Inhibits Human Mast Cell Activation Via Epigenetic Regulation of FcepsilonRI-mediated Signaling. Allergy (2020) 75(8):196274. doi: 10.1111/all.14254

47. Seppo AE, Savilahti EM, Berin MC, Sampson HA, Jarvinen KM. Breast Milk IgA to Foods has Different Epitope Specificity Than Serum IgA-Evidence for Entero-Mammary Link for Food-Specific Iga? Clin Exp Allergy (2017) 47 (10):1275-84. doi: 10.1111/cea.12945

48. Flohr C, Henderson AJ, Kramer MS, Patel R, Thompson J, Rifas-Shiman SL, et al. Effect of an Intervention to Promote Breastfeeding on Asthma, Lung Function, and Atopic Eczema At Age 16 Years: Follow-Up of the PROBIT Randomized Trial. JAMA Pediatr (2018) 172(1):e174064. doi: 10.1001/ jamapediatrics.2017.4064

49. Vandenplas Y, Abuabat A, Al-Hammadi S, Aly GS, Miqdady MS, Shaaban SY, et al. Middle East Consensus Statement on the Prevention, Diagnosis, and Management of Cow's Milk Protein Allergy. Pediatr Gastroenterol Hepatol Nutr (2014) 17(2):61-73. doi: 10.5223/pghn.2014.17.2.61

50. Fritsché R, Pahud JJ, Pecquet S, Pfeifer A. Induction of Systemic Immunologic Tolerance to Beta-Lactoglobulin by Oral Administration of a Whey Protein Hydrolysate. J Allergy Clin Immunol (1997) 100(2):266-73. doi: 10.1016/S0091-6749(97)70235-5

51. Inuo C, Tanaka K, Nakajima Y, Yamawaki K, Matsubara T, Iwamoto $H$, et al. Tolerability of Partially and Extensively Hydrolyzed Milk Formulas in Children With Cow's Milk Allergy. Asia Pac J Clin Nutr (2019) 28(1):49-56. doi: 10.6133/apjen.201903_28(1).0008

52. Szajewska H, Horvath A. A Partially Hydrolyzed 100\% Whey Formula and the Risk of Eczema and Any Allergy: An Updated Meta-Analysis. World Allergy Organ J (2017) 10(1):27. doi: 10.1186/s40413-017-0158-Z

53. von Berg A, Koletzko S, Grubl A, Filipiak-Pittroff B, Wichmann HE, Bauer CP, et al. The Effect of Hydrolyzed Cow's Milk Formula for Allergy Prevention in the First Year of Life: The German Infant Nutritional Intervention Study, A Randomized Double-Blind Trial. J Allergy Clin Immunol (2003) 111(3):533-40. doi: 10.1067/mai.2003.101

54. von Berg A, Koletzko S, Filipiak-Pittroff B, Laubereau B, Grubl A, Wichmann HE, et al. Certain Hydrolyzed Formulas Reduce the Incidence of Atopic Dermatitis But Not That of Asthma: Three-Year Results of the German Infant Nutritional Intervention Study. J Allergy Clin Immunol (2007) 119(3):718-25. doi: 10.1016/j.jaci.2006.11.017

55. von Berg A, Filipiak-Pittroff B, Kramer U, Link E, Bollrath C, Brockow I, et al. Preventive Effect of Hydrolyzed Infant Formulas Persists Until Age 6 Years: Long-Term Results From the German Infant Nutritional Intervention Study (Gini). J Allergy Clin Immunol (2008) 121(6):1442-7. doi: 10.1016/ j.jaci.2008.04.021

56. von Berg A, Filipiak-Pittroff B, Kramer U, Hoffmann B, Link E, Beckmann C, et al. Allergies in High-Risk Schoolchildren After Early Intervention With Cow's Milk Protein Hydrolysates: 10-Year Results From the German Infant Nutritional Intervention (GINI) Study. J Allergy Clin Immunol (2013) 131 (6):1565-73. doi: 10.1016/j.jaci.2013.01.006

57. von Berg A, Filipiak-Pittroff B, Schulz H, Hoffmann U, Link E, Sussmann M, et al. Allergic Manifestation 15 Years After Early Intervention With Hydrolyzed Formulas-the GINI Study. Allergy (2016) 71(2):210-9. doi: 10.1111/all.12790

58. Gappa M, Filipiak-Pittroff B, Libuda L, von Berg A, Koletzko S, Bauer CP, et al. Long-Term Effects of Hydrolyzed Formulae on Atopic Diseases in the GINI Study. Allergy (2020) 43. doi: 10.1111/all.14709

59. Boyle RJ, Tang ML, Chiang WC, Chua MC, Ismail I, Nauta A, et al. Prebiotic-Supplemented Partially Hydrolyzed Cow's Milk Formula for the
Prevention of Eczema in High-Risk Infants: A Randomized Controlled Trial. Allergy (2016) 71(5):701-10. doi: 10.1111/all.12848

60. Snijders BE, Thijs C, van Ree R, van den Brandt PA. Age At First Introduction of Cow Milk Products and Other Food Products in Relation to Infant Atopic Manifestations in the First 2 Years of Life: The KOALA Birth Cohort Study. Pediatrics (2008) 122(1):e115-22. doi: 10.1542/ peds.2007-1651

61. Katz Y, Rajuan N, Goldberg MR, Eisenberg E, Heyman E, Cohen A, et al. Early Exposure to Cow's Milk Protein is Protective Against IgE-Mediated Cow's Milk Protein Allergy. J Allergy Clin Immunol (2010) 126(1):77-82 e1. doi: 10.1016/j.jaci.2010.04.020

62. Urashima M, Mezawa H, Okuyama M, Urashima T, Hirano D, Gocho N, et al. Primary Prevention of Cow's Milk Sensitization and Food Allergy by Avoiding Supplementation With Cow's Milk Formula At Birth: A Randomized Clinical Trial. JAMA Pediatr (2019) 173(12):1137-45. doi: 10.1001/jamapediatrics.2019.3544

63. Bhanegaonkar A, Horodniceanu EG, Ji X, Detzel P, Boguniewicz M, Chamlin $S$, et al. Economic Burden of Atopic Dermatitis in High-Risk Infants Receiving Cow's Milk or Partially Hydrolyzed 100\% Whey-Based Formula. J Pediatr (2015) 166(5):1145-51.e3. doi: 10.1016/j.jpeds.2015.02.017

64. Halken S, Muraro A, de Silva D, Khaleva E, Angier E, Arasi S, et al. EAACI Guideline: Preventing the Development of Food Allergy in Infants and Young Children (2020 Update). Pediatr Allergy Immunol (2021). doi: 10.1111/pai.13496

65. Osborn DA, Sinn JK, Jones LJ. Infant Formulas Containing Hydrolyzed Protein for Prevention of Allergic Disease. Cochrane Database Syst Rev (2018) 10(10):Cd003664. doi: 10.1002/14651858.CD003664.pub6

66. Palmer DJ, Metcalfe J, Makrides M, Gold MS, Quinn P, West CE, et al. Early Regular Egg Exposure in Infants With Eczema: A Randomized Controlled Trial. J Allergy Clin Immunol (2013) 132(2):387-92.e1. doi: 10.1016/ j.jaci.2013.05.002

67. Du Toit G, Roberts G, Sayre PH, Plaut M, Bahnson HT, Mitchell H, et al. Identifying Infants At High Risk of Peanut Allergy: The Learning Early About Peanut Allergy (LEAP) Screening Study. J Allergy Clin Immunol (2013) 131(1):135-43 e1-12. doi: 10.1016/j.jaci.2012.09.015

68. Du Toit G, Roberts G, Sayre PH, Bahnson HT, Radulovic S, Santos AF, et al. Randomized Trial of Peanut Consumption in Infants At Risk for Peanut Allergy. N Engl J Med (2015) 372(9):803-13. doi: 10.1056/NEJMoa1414850

69. Onizawa Y, Noguchi E, Okada M, Sumazaki R, Hayashi D. The Association of the Delayed Introduction of Cow's Milk With IgE-Mediated Cow's Milk Allergies. J Allergy Clin Immunol In Pract (2016) 4(3):481-8.e2. doi: 10.1016/ j.jaip.2016.01.012

70. Greer FR, Sicherer SH, Burks WA, Committee on Nutrition. Early Introduction of Allergenic Complementary Foods. Pediatr (2019) 143 (4):1-11. doi: 10.1542/peds.2019-0281

71. Greenhawt M, Fleischer DM, Spergel JM. Is It Time for a Randomized Trial on Early Introduction of Milk? J Allergy Clin Immunol Pract (2016) 4 (3):489-90. doi: 10.1016/j.jaip.2016.03.013

72. Brick T, Hettinga K, Kirchner B, Pfaffl MW, Ege MJ. The Beneficial Effect of Farm Milk Consumption on Asthma, Allergies, and Infections: From MetaAnalysis of Evidence to Clinical Trial. J Allergy Clin Immunol In Pract (2020) 8(3):878-89 e3. doi: 10.1016/j.jaip.2019.11.017

73. von Mutius E, Vercelli D. Farm Living: Effects on Childhood Asthma and Allergy. Nat Rev Immunol (2010) 10(12):861-8. doi: 10.1038/nri2871

74. Host A, Samuelsson EG. Allergic Reactions to Raw, Pasteurized, and Homogenized/Pasteurized Cow Milk: A Comparison. A Double-Blind Placebo-Controlled Study in Milk Allergic Children. Allergy (1988) 43 (2):113-8. doi: 10.1111/j.1398-9995.1988.tb00404.x

75. Abbring S, Xiong L, Diks MAP, Baars T, Garssen J, Hettinga K, et al. Loss of Allergy-Protective Capacity of Raw Cow's Milk After Heat Treatment Coincides With Loss of Immunologically Active Whey Proteins. Food Funct (2020) 11(6):4982-93. doi: 10.1039/D0FO01175D

76. Horimukai K, Morita K, Narita M, Kondo M, Kitazawa H, Nozaki M, et al. Application of Moisturizer to Neonates Prevents Development of Atopic Dermatitis. J Allergy Clin Immunol (2014) 134(4):824-30.e6. doi: 10.1016/ j.jaci.2014.07.060

77. Odhiambo JA, Williams HC, Clayton TO, Robertson CF, Asher MI, Group IPTS. Global Variations in Prevalence of Eczema Symptoms in Children 
From ISAAC Phase Three. J Allergy Clin Immunol (2009) 124(6):12518.e23. doi: 10.1016/j.jaci.2009.10.009

78. Williams H, Stewart A, von Mutius E, Cookson W, Anderson HR. International Study of A, Et al. Is Eczema Really on the Increase Worldwide? J Allergy Clin Immunol (2008) 121(4):947-54.e15. doi: 10.1016/j.jaci.2007.11.004

79. Boguniewicz M, Leung DY. Atopic Dermatitis: A Disease of Altered Skin Barrier and Immune Dysregulation. Immunol Rev (2011) 242(1):233-46. doi: 10.1111/j.1600-065X.2011.01027.x

80. Leung DY. Why is Eczema Herpeticum Unexpectedly Rare? Antiviral Res (2013) 98(2):153-7. doi: 10.1016/j.antiviral.2013.02.010

81. Perrett KP, Peters RL. Emollients for Prevention of Atopic Dermatitis in Infancy. Lancet (London England) (2020) 395(10228):923-4. doi: 10.1016/ S0140-6736(19)33174-5

82. Prescott SL, Dunstan JA. Prenatal Fatty Acid Status and Immune Development: The Pathways and the Evidence. Lipids (2007) 42(9):80110. doi: 10.1007/s11745-007-3030-z

83. Dunstan JA, Mitoulas LR, Dixon G, Doherty DA, Hartmann PE, Simmer K, et al. The Effects of Fish Oil Supplementation in Pregnancy on Breast Milk Fatty Acid Composition Over the Course of Lactation: A Randomized Controlled Trial. Pediatr Res (2007) 62(6):689-94. doi: 10.1203/ PDR.0b013e318159a93a

84. Krauss-Etschmann S, Hartl D, Rzehak P, Heinrich J, Shadid R, Del Carmen Ramirez-Tortosa M, et al. Decreased Cord Blood IL-4, IL-13, and CCR4 and Increased TGF-Beta Levels after Fish Oil Supplementation of Pregnant Women. J Allergy Clin Immunol (2008) 121(2):464-70.e6. doi: 10.1016/ j.jaci.2007.09.018

85. Palmer DJ, Sullivan T, Gold MS, Prescott SL, Heddle R, Gibson RA, et al. Effect of N-3 Long Chain Polyunsaturated Fatty Acid Supplementation in Pregnancy on Infants' Allergies in First Year of Life: Randomised Controlled Trial. BMJ (2012) 344:e184. doi: 10.1136/bmj.e184

86. Best KP, Gold M, Kennedy D, Martin J, Makrides M. Omega-3 Long-Chain PUFA Intake During Pregnancy and Allergic Disease Outcomes in the Offspring: A Systematic Review and Meta-Analysis of Observational Studies and Randomized Controlled Trials. Am J Clin Nutr (2016) 103(1):128-43. doi: 10.3945/ajen.115.111104

87. Osborn DA, Sinn JK. Prebiotics in Infants for Prevention of Allergy. Cochrane Database Syst Rev (2013) 3:Cd006474. doi: 10.1002/14651858. CD006474.pub3

88. Donovan SM, Wang M, Li M, Friedberg I, Schwartz SL, Chapkin RS. HostMicrobe Interactions in the Neonatal Intestine: Role of Human Milk Oligosaccharides. Adv Nutr (2012) 3(3):450S-5S. doi: 10.3945/an.112.001859

89. Haarman M, Knol J. Quantitative Real-Time PCR Analysis of Fecal Lactobacillus Species in Infants Receiving a Prebiotic Infant Formula. Appl Environ Microbiol (2006) 72(4):2359-65. doi: 10.1128/AEM.72.4.23592365.2006

90. Scholtens PA, Alles MS, Bindels JG, van der Linde EG, Tolboom JJ, Knol J. Bifidogenic Effects of Solid Weaning Foods With Added Prebiotic Oligosaccharides: A Randomised Controlled Clinical Trial. J Pediatr Gastroenterol Nutr (2006) 42(5):553-9. doi: 10.1097/01.mpg.0000221887. 28877.c7

91. Moro G, Arslanoglu S, Stahl B, Jelinek J, Wahn U, Boehm G. A Mixture of Pprebiotic Oligosaccharides Reduces the Incidence of Atopic Dermatitis During the First Six Months of Age. Arch Dis Child (2006) 91(10):814-9. doi: 10.1136/adc.2006.098251

92. Gruber C, van Stuijvenberg M, Mosca F, Moro G, Chirico G, Braegger CP, et al. Reduced Occurrence of Early Atopic Dermatitis Because of Immunoactive Prebiotics Among Low-Atopy-Risk Infants. J Allergy Clin Immunol (2010) 126(4):791-7. doi: 10.1016/j.jaci.2010.07.022

93. Wopereis H, Sim K, Shaw A, Warner JO, Knol J, Kroll JS. Intestinal Microbiota in Infants At High Risk for Allergy: Effects of Prebiotics and Role in Eczema Development. J Allergy Clin Immunol (2018) 141(4):133442.e5. doi: 10.1016/j.jaci.2017.05.054

94. Bode L. The Functional Biology of Human Milk Oligosaccharides. Early Hum Dev (2015) 91(11):619-22. doi: 10.1016/j.earlhumdev.2015.09.001

95. Thongaram T, Hoeflinger JL, Chow J, Miller MJ. Human Milk Oligosaccharide Consumption by Probiotic and Human-Associated Bifidobacteria and Lactobacilli. J Dairy Sci (2017) 100(10):7825-33. doi: $10.3168 /$ jds.2017-12753
96. Castillo-Courtade L, Han S, Lee S, Mian FM, Buck R, Forsythe P. Attenuation of Food Allergy Symptoms Following Treatment With Human Milk Oligosaccharides in A Mouse Model. Allergy (2015) 70 (9):1091-102. doi: 10.1111/all.12650

97. Pretorius R, Prescott SL, Palmer DJ. Taking a Prebiotic Approach to Early Immunomodulation for Allergy Prevention. Expert Rev Clin Immunol (2018) 14(1):43-51. doi: 10.1080/1744666X.2018.1411191

98. Seppo AE, Autran CA, Bode L, Jarvinen KM. Human Milk Oligosaccharides and Development of Cow's Milk Allergy in Infants. J Allergy Clin Immunol (2017) 139(2):708-11.e5. doi: 10.1016/j.jaci.2016.08.031

99. Strachan DP. Hay Fever, Hygiene, and Household Size. BMJ (1989) 299 (6710):1259-60. doi: 10.1136/bmj.299.6710.1259

100. Cuello-Garcia CA, Brozek JL, Fiocchi A, Pawankar R, Yepes-Nunez JJ, Terracciano L, et al. Probiotics for the Prevention of Allergy: A Systematic Review and Meta-Analysis of Randomized Controlled Trials. J Allergy Clin Immunol (2015) 136(4):952-61. doi: 10.1016/j.jaci.2015.04.031

101. Fiocchi A, Pawankar R, Cuello-Garcia C, Ahn K, Al-Hammadi S, Agarwal A, et al. World Allergy Organization-Mcmaster University Guidelines for Allergic Disease Prevention (Glad-P): Probiotics. World Allergy Organ J (2015) 8(1):4. doi: 10.1186/s40413-015-0055-2

102. Boyle RJ, Ismail IH, Kivivuori S, Licciardi PV, Robins-Browne RM, Mah LJ, et al. Lactobacillus GG Treatment During Pregnancy for the Prevention of Eczema: A Randomized Controlled Trial. Allergy (2011) 66(4):509-16. doi: 10.1111/j.1398-9995.2010.02507.x

103. D’Auria E, Salvatore S, Pozzi E, Mantegazza C, Sartorio MUA, Pensabene L, et al. Cow's Milk Allergy: Immunomodulation by Dietary Intervention. Nutrients (2019) 11(6):509-16. doi: 10.3390/nu11061399

104. Heine RG. Food Allergy Prevention and Treatment by Targeted Nutrition. Ann Nutr Metab (2018) 72(Suppl 3):33-45. doi: 10.1159/000487380

105. Koletzko S, Niggemann B, Arato A, Dias JA, Heuschkel R, Husby S, et al. Diagnostic Approach and Management of Cow's-Milk Protein Allergy in Infants and Children: ESPGHAN Gi Committee Practical Guidelines. J Pediatr Gastroenterol Nutr (2012) 55(2):221-9. doi: 10.1097/MPG.0b013e31825c9482

106. Lambers TT, Gloerich J, van Hoffen E, Alkema W, Hondmann DH, van Tol EA. Clustering Analyses in Peptidomics Revealed That Peptide Profiles of Infant Formulae are Descriptive. Food Sci Nutr (2015) 3(1):81-90. doi: $10.1002 /$ fsn 3.196

107. Chauveau A, Nguyen-Grosjean VM, Jacquenet S, Richard C, Mouton-Faivre C. Immediate Hypersensitivity to Extensively Hydrolyzed Formulas: An Important Reminder. Pediatr Allergy Immunol (2016) 27(5):541-3. doi: 10.1111/pai.12556

108. Fiocchi A, Dahda L, Dupont C, Campoy C, Fierro V, Nieto A. Cow's Milk Allergy: Towards an Update of DRACMA Guidelines. World Allergy Organ J (2016) 9(1):35. doi: 10.1186/s40413-016-0125-0

109. Taylor RR, Sladkevicius E, Panca M, Lack G, Guest JF. Cost-Effectiveness of Using an Extensively Hydrolyzed Formula Compared to an Amino Acid Formula as First-Line Treatment for Cow Milk Allergy in the UK. Pediatr Allergy Immunol (2012) 23(3):240-9. doi: 10.1111/j.1399-3038.2011.01262.x

110. Sladkevicius E, Nagy E, Lack G, Guest JF. Resource Implications and Budget Impact of Managing Cow Milk Allergy in the UK. J Med Econ (2010) 13 (1):119-28. doi: 10.3111/13696990903543242

111. Fiocchi A, Schunemann HJ, Brozek J, Restani P, Beyer K, Troncone R, et al. Diagnosis and Rationale for Action Against Cow's Milk Allergy (DRACMA): A Summary Report. J Allergy Clin Immunol (2010) 126(6):1119-28.e12. doi: 10.1016/j.jaci.2010.10.011

112. Hill DJ, Heine RG, Cameron DJ, Francis DE, Bines JE. The Natural History of Intolerance to Soy and Extensively Hydrolyzed Formula in Infants With Multiple Food Protein Intolerance. J Pediatr (1999) 135(1):118-21. doi: 10.1016/S0022-3476(99)70341-0

113. Nowak-Wegrzyn A, Chatchatee P. Mechanisms of Tolerance Induction. Ann Nutr Metab (2017) 70 Suppl 2:7-24. doi: 10.1159/000457915

114. Candy DCA, Van Ampting MTJ, Oude Nijhuis MM, Wopereis H, Butt AM, Peroni DG, et al. A Synbiotic-Containing Amino-Acid-Based Formula Improves Gut Microbiota in Non-IgE-mediated Allergic Infants. Pediatr Res (2018) 83(3):677-86. doi: 10.1038/pr.2017.270

115. Gonzalez Ballesteros LF, Ma NS, Gordon RJ, Ward L, Backeljauw P, Wasserman $\mathrm{H}$, et al. Unexpected Widespread Hypophosphatemia and Bone Disease Associated With Elemental Formula Use in Infants and Children. Bone (2017) 97:287-92. doi: 10.1016/j.bone.2017.02.003 
116. Akhtar Ali S, Mathalikunnel A, Bhardwaj V, Braskett M, Pitukcheewanont P. Nutritional Hypophosphatemic Rickets Secondary to Neocate ${ }^{\circledR}$ Use. Osteoporosis Int (2019) 30(9):1887-91. doi: 10.1007/s00198-019-04836-8

117. Eswarakumar AS, Ma NS, Ward LM, Backeljauw P, Wasserman H, Weber DR, et al. Long-Term Follow-up of Hypophosphatemic Bone Disease Associated With Elemental Formula Use: Sustained Correction of Bone Disease After Formula Change or Phosphate Supplementation. Clin Pediatr (2020), 9922820941097. doi: 10.1177/0009922820941097

118. Marino LV, Venkatesh P, Ho A, Beattie RM, Bharucha T. Hypophosphataemia in Infants With CHD Treated With Amino Acid Infant Formula. Cardiol Young (2018) 28(11):1370-4. doi: 10.1017/S1047951118001324

119. Uday S, Sakka S, Davies JH, Randell T, Arya V, Brain C, et al. Elemental Formula Associated Hypophosphataemic Rickets. Clin Nutr (2019) 38 (5):2246-50. doi: 10.1016/j.clnu.2018.09.028

120. Bergwitz C, Eussen S, Janssens P, Visser M, Carpenter TO, van Helvoort A. Different Elemental Infant Formulas Show Equivalent Phosphorus and Calcium Bioavailability in Healthy Volunteers. Nutr Res (2021) 85:71-83. doi: 10.1016/j.nutres.2020.11.004

121. Yanagida N, Sato S, Asaumi T, Okada Y, Ogura K, Ebisawa M. A SingleCenter, Case-Control Study of Low-Dose-Induction Oral Immunotherapy With Cow's Milk. Int Arch Allergy Immunol (2015) 168(2):131-7. doi: $10.1159 / 000442157$

122. Kim JS, Nowak-Wegrzyn A, Sicherer SH, Noone S, Moshier EL, Sampson HA. Dietary Baked Milk Accelerates the Resolution of Cow's Milk Allergy in Children. J Allergy Clin Immunol (2011) 128(1):125-31.e2. doi: 10.1016/j.jaci.2011.04.036

123. Kido J, Nishi N, Sakaguchi M, Matsumoto T. Most Cases of Cow's Milk Allergy are Able to Ingest a Partially Hydrolyzed Formula. Ann Allergy Asthma Immunol (2015) 115(4):330-1.e2. doi: 10.1016/j.anai.2015.07.013

124. Nowak-Wegrzyn A, Czerkies L, Reyes K, Collins B, Heine RG. Confirmed Hypoallergenicity of a Novel Whey-Based Extensively Hydrolyzed Infant Formula Containing Two Human Milk Oligosaccharides. Nutrients (2019) 11(7):330-1.e2. doi: 10.3390/nu11071447

125. Paparo L, Nocerino R, Bruno C, Di Scala C, Cosenza L, Bedogni G, et al. Randomized Controlled Trial on the Influence of Dietary Intervention on Epigenetic Mechanisms in Children With Cow's Milk Allergy: The EPICMA Study. Sci Rep (2019) 9(1):2828. doi: 10.1038/s41598-019-45226-8

126. Berni Canani R, Sangwan N, Stefka AT, Nocerino R, Paparo L, Aitoro R, et al. Lactobacillus Rhamnosus GG-Supplemented Formula Expands ButyrateProducing Bacterial Strains in Food Allergic Infants. ISME J (2016) 10 (3):742-50. doi: 10.1038/ismej.2015.151

127. Nutten S, Maynard F, Jarvi A, Rytz A, Simons PJ, Heine RG, et al. Peptide Size Profile and Residual Immunogenic Milk Protein or Peptide Content in Extensively Hydrolyzed Infant Formulas. Allergy (2020) 75(6):1446-9. doi: 10.1111/all.14098

128. Shamji MH, Durham SR. Mechanisms of Allergen Immunotherapy for Inhaled Allergens and Predictive Biomarkers. J Allergy Clin Immunol (2017) 140(6):1485-98. doi: 10.1016/j.jaci.2017.10.010

129. Knol EF, de Jong NW, Ulfman LH, Tiemessen MM. Management of Cow's Milk Allergy From An Immunological Perspective: What are the Options? Nutrients (2019) 11(11):1485-98. doi: 10.3390/nu11112734

130. Zakeri A, Russo M. Dual Role of Toll-like Receptors in Human and Experimental Asthma Models. Front Immunol (2018) 9:1027. doi: 10.3389/ fimmu.2018.01027

131. Kiewiet MBG, Dekkers R, Gros M, van Neerven RJJ, Groeneveld A, de Vos P, et al. Toll-Like Receptor Mediated Activation is Possibly Involved in
Immunoregulating Properties of Cow's Milk Hydrolysates. PloS One (2017) 12(6):e0178191. doi: 10.1371/journal.pone.0178191

132. Ball HB, Luyt D. Home-Based Cow's Milk Reintroduction Using a Milk Ladder in Children Less Than 3 Years Old With IgE-mediated Cow's Milk Allergy. Clin Exp Allergy (2019) 49(6):911-20. doi: 10.1111/cea.13366

133. Berni Canani R, Di Costanzo M, Bedogni G, Amoroso A, Cosenza L, Di Scala C, et al. Extensively Hydrolyzed Casein Formula Containing Lactobacillus Rhamnosus GG Reduces the Occurrence of Other Allergic Manifestations in Children With Cow's Milk Allergy: 3-Year Randomized Controlled Trial. J Allergy Clin Immunol (2017) 139(6):1906-13.e4. doi: 10.1016/ j.jaci.2016.10.050

134. Madsen CB, Hattersley S, Allen KJ, Beyer K, Chan CH, Godefroy SB, et al. Can We Define a Tolerable Level of Risk in Food Allergy? Report from a EuroPrevall/UK Food Standards Agency workshop. Clin Exp Allergy (2012) 42(1):30-7. doi: 10.1111/j.1365-2222.2011.03868.x

135. Fiocchi A, Brozek J, Schunemann H, Bahna SL, von Berg A, Beyer K, et al. World Allergy Organization (Wao) Diagnosis and Rationale for Action Against Cow's Milk Allergy (Dracma) Guidelines. World Allergy Organ J (2010) 3(4):57-161. doi: 10.1097/WOX.0b013e3181defeb9

136. Wood LG, Lagleva M, Shah S, Berthon BS, Galbraith S, Henry R, et al. Dietary Changes in Migrant Adolescents With Increasing Length of Stay in Australia and Associated Risk of Wheeze-a Retrospective, Cross Sectional Study. BMC Pediatr (2015) 15:102. doi: 10.1186/s12887-015-0420-x

137. Tchidjou HK, Vescio MF, Serafinelli J, Giampaolo R, Jenkner A, Tadonkeng MC, et al. Susceptibility to Allergy in Adoptive Children: A Cross-Sectional Study At "Bambino Gesù Children's Hospital”. Ital J Pediatr (2018) 44(1):3. doi: 10.1186/s13052-017-0440-2

138. Piccinni MP, Mecacci F, Sampognaro S, Manetti R, Parronchi P, Maggi E, et al. Aeroallergen Sensitization Can Occur During Fetal Life. Int Arch Allergy Immunol (1993) 102(3):301-3. doi: 10.1159/000236541

139. Prescott SL, Pawankar R, Allen KJ, Campbell DE, Sinn J, Fiocchi A, et al. A Global Survey of Changing Patterns of Food Allergy Burden in Children. World Allergy Organ J (2013) 6(1):21. doi: 10.1186/1939-4551-6-21

140. Muraro A, Halken S, Arshad SH, Beyer K, Dubois AE, Du Toit G, et al. EAACI Food Allergy and Anaphylaxis Guidelines. Primary prevention of food allergy. Allergy (2014) 69(5):590-601. doi: 10.1111/all.12398

141. Fleischer DM, Spergel JM, Assa'ad AH, Pongracic JA. Primary Prevention of Allergic Disease Through Nutritional Interventions. J Allergy Clin Immunol In Pract (2013) 1(1):29-36. doi: 10.1016/j.jaip.2012.09.003

Conflict of Interest: UK, JN, and LM are employees of FrieslandCampina.

The remaining authors declare that the research was conducted in the absence of any commercial or financial relationships that could be construed as a potential conflict of interest.

Copyright (c) 2021 Zepeda-Ortega, Goh, Xepapadaki, Sprikkelman, Nicolaou, Hernandez, Latiff, Yat, Diab, Hussaini, Setiabudiawan, Kudla, van Neerven, Muhardi and Warner. This is an open-access article distributed under the terms of the Creative Commons Attribution License (CC BY). The use, distribution or reproduction in other forums is permitted, provided the original author(s) and the copyright owner(s) are credited and that the original publication in this journal is cited, in accordance with accepted academic practice. No use, distribution or reproduction is permitted which does not comply with these terms. 